\title{
“Getting Ready for School:" A Preliminary Evaluation of a Parent-Focused School-Readiness Program
}

\author{
Kimberly G. Noble, ${ }^{1}$ Helena Duch, ${ }^{2}$ Maria Eugenia Darvique, ${ }^{2}$ Alexandra Grundleger, ${ }^{2}$ \\ Carmen Rodriguez, ${ }^{2}$ and Cassie Landers ${ }^{2}$ \\ ${ }^{1}$ Department of Pediatrics and GH Sergievsky Center, College of Physicians and Surgeons, Columbia University Medical Center, \\ Columbia University New York, NY 10032, USA \\ ${ }^{2}$ Department of Population and Family Health, Mailman School of Public Health, Columbia University Medical Center, \\ Columbia University New York, NY 10032, USA
}

Correspondence should be addressed to Helena Duch, hd90@columbia.edu

Received 9 August 2011; Revised 12 January 2012; Accepted 12 January 2012

Academic Editor: Susan A. Gelman

Copyright ( 2012 Kimberly G. Noble et al. This is an open access article distributed under the Creative Commons Attribution License, which permits unrestricted use, distribution, and reproduction in any medium, provided the original work is properly cited.

Children from disadvantaged backgrounds tend to start school with fewer school readiness skills than their more advantaged peers. Emergent literacy and math skills play an important role in this gap. The family is essential in helping children build these skills, and the active involvement of families is crucial to the success of any intervention for young children. The Getting Ready for School (GRS) program is a parent-focused curriculum designed to help parents equip their children with the skills and enthusiasm necessary for learning when they start school. Parents meet in weekly workshops led by a trained facilitator and implement the curriculum at home with their children. The objective of this pilot study was to assess the promise of the GRS intervention in children participating in an urban Head Start program and to explore parents' responses to the intervention. We hypothesized that participation in GRS would improve school readiness in literacy and math skills, relative to participation in business-as-usual Head Start. Four Head Start classrooms (two randomly selected "intervention" and two "comparison" classrooms) participated in this study. Preliminary analyses suggest that GRS improves school readiness over and above a Head Start-as-usual experience. Implications for early childhood programs and policies are discussed.

\section{Introduction}

School readiness, or the development of the cognitive, social, and emotional skills necessary for children to enter school ready to learn, creates the foundation for academic success, physical and mental health, and general well-being [1]. Unfortunately, socioeconomic disadvantage tends to lead to large gaps in the development of both the cognitive [2-5] and socioemotional skills $[6-8]$ underlying school readiness $[9$, $10]$.

By the time children enter school, disadvantaged children tend to score between one-half and one-full standard deviation lower than other children on reading and math achievement tests [8]. Additionally, socioeconomic disadvantage is associated with problems in children's self-regulation, including difficulties controlling impulses and regulating emotions $[3,4,7,8]$. Disparities in cognitive and socioemotional development are not ameliorated during the early elementary years. Indeed, gaps in achievement tend to increase with age $[10,11]$, having vast implications for future life achievement [12-15]. Disadvantaged children of Latino descent are at particular risk for poor school readiness [16-18] and subsequent school failure [19]. Quality preschool programs can reduce the school-readiness gap to some extent [20,21], although individual interventions tend to have small effect sizes [22] and do not close the achievement gap.

Head Start was founded on the principle that child development is the product of multiple levels of interaction, with both parents and teachers playing unique and important roles [23]. Traditionally, add-on interventions to promote school readiness tend to be classroom based [20]. When considered separately, center-based programs tend to show 
stronger effects than home-based programs [12]. On one hand, this underscores the importance of the classroom environment. However, parents and teachers independently influence child development [23], with parenting skills directly related to children's later cognitive development and academic achievement $[12,13,24]$.

Bioecological theory predicts that parents play a particularly important role in promoting early childhood school readiness [25]. In particular, this theory states that "proximal processes" are a key factor in child development [26-28]. Proximal processes are defined as enduring, complex, reciprocal interactions between a child and the people in his or her immediate environment [28]. Parents may be the most proximal (and therefore most powerful) external influences in children's lives. To the extent that this theory is accurate, we would predict that an intervention which successfully and positively influences parenting may wield particularly strong effects on child development and school readiness.

In the following, two key domains of school readiness are outlined. Evidence regarding the means by which parents contribute to each is discussed.

1.1. Emergent Literacy and Parents. Emergent literacy refers to the skills and reading-like behaviors that are developmental precursors to their more advanced counterparts [29]. It is a key component of school readiness, and early disparities in emergent literacy in preschool tend to be exacerbated through the elementary years [30]. Effective teaching of these skills requires active involvement of the child. For instance, shared book reading benefits oral language development most substantially when the adult actively engages the child in "dialogic reading," in which the adult asks questions and prompts the child to "become the storyteller" [31-33]. Similarly, explicit teaching about print increases letter knowledge and later reading ability, while informal print exposure does not $[29,34,35]$.

The degree to which parents actively engage children in explicit practice with letters and sounds is related to children's understanding of printed words [35] controlling for children's independent pursuit of these activities [36]. Randomized trials suggest that when disadvantaged parents are taught strategies to actively engage children in reading, children's emergent literacy skills improve [5, 33, 37]. Further, greater improvements are seen when children are engaged in such strategies both at home and school, relative to school alone $[5,33]$.

1.2. Emergent Mathematics Skills and Parents. As with emergent literacy, disadvantaged children are less likely to exhibit well-developed mathematics skills and knowledge than their more advantaged counterparts [38-40]. This achievement gap is measurable by preschool and continues throughout the school years [41, 42].

Prior to starting school, young children use math concepts in their play and daily lives [43, 44], and a general learning path for the acquisition of these concepts has been identified for preschoolers $[45,46]$. As with language development, passive exposure to math is not enough; structured educational experiences are necessary. While children's everyday activities and play can be excellent vehicles, these activities may not suffice without scaffolding and guidance [46].

Exposure to math concepts in the home can have a positive impact on school readiness [47]. However, lowincome homes tend to provide less support for mathematical development relative to their middle-income counterparts $[48,49]$. Disadvantaged families are more likely to focus on simpler topics such as counting and shape recognition, rather than on more complex processes such as numerical or geometric reasoning [50]. Further, low-income parents frequently have different expectations about their role in teaching mathematics to their children [49]. One program designed to address these disparities, the Family Mathematics Curriculum (FMC), provides low-income families with a structured mathematical intervention in which parents and children attend family mathematics classes and also have access to math materials for use at home [51]. In two small evaluations with Head Start families, researchers found that children who participated in FMC with their parents had significantly higher scores in the areas of enumeration, numerical reasoning, and an overall math composite relative to children in a control group [51]. This supports the premise that, with adequate supports and materials, parents can have a significant impact on young children's mathematical skills, enhancing overall school readiness.

1.3. The Getting Ready for School Intervention. The Getting Ready for School (GRS) curriculum was originally designed as an intervention for parents in Central and Eastern Europe with limited or no access to preschool. The goal was to teach parents to create more effective home learning environments for their preschool-aged children, by supporting and expanding parents' ability to promote the literacy and math skills children need for success in school.

Subsequently, the GRS curriculum has been implemented in parent groups in a small number of Head Start centers in the US. Translation of the materials into Spanish was completed by a team of bilingual, bicultural staff members at the Head Start where the present study took place, led by one of the lead authors on this study (H. Duch). The GRS curriculum recently received national attention when it was selected by the National Head Start Family Literacy Center as part of their training for $96 \mathrm{Head}$ Start programs participating in the SPARC (Strengthening Partnerships and Resources in Communities for Literacy) program. In addition, the materials were made available to any interested Head Start program. Since May 2010, over 600 Head Start programs around the country have requested the GRS materials and training. As wide dissemination of the materials began to take place, research examining the potential feasibility and efficacy of this intervention became critical.

1.3.1. Structure of the Intervention. GRS is a nine-unit curriculum of activities, available in both English and Spanish, 
designed to help parents promote young children's schoolreadiness skills in reading and math. Parents are shown how to use the activities through weekly group sessions led by a Parent Facilitator. The content of the curriculum is described in detail below. Briefly, the materials include the following.

(a) Parent Activity Guide. This guide is a written set of activity suggestions that parents can use with their children. Activities explain how to use the children's materials, provide additional literacy and math activities, and suggest ways to modify or enrich the activities depending upon their child's needs. The Parent Activity Guide is written with pictorial demonstrations of activities, with text requiring only a minimal literacy level.

(b) Children's Activity Sets. These are nine sets of materials focusing on literacy and math designed for use in the above activities. Each set includes pictures, games, and other materials. These materials are distributed in children's backpacks, containing the book of activities as well as crayons, scissors, and paper.

(c) Facilitator's Guide. This Guide provides a set of lesson plans for the Parent Facilitator in running the weekly parent sessions. A written set of activity suggestions is provided that explains how to teach parents to use the children's materials. The Facilitator's Guide also provides suggestions on ways to modify or enrich the activities depending upon the child's needs. Finally, the Facilitator's Guide provides Parent Facilitators with guidance on soliciting reports of parent experiences with the activity sets.

(d) Train-the-Trainer Guide. This guide teaches Parent Facilitators how to run effective parent meetings. It includes a review of early math and literacy development, as well as exercises to help Facilitators develop problem-solving skills around common issues that parents may describe.

1.3.2. Parent Workshops. Through weekly two-hour workshops, Parent Facilitators disseminate and explore the materials with parents, facilitating a parent-teaching process. The materials are designed to be open-ended and help parents tailor activities to their children's interests and abilities. For example, to encourage children's math development, parents are shown how to teach number concepts using games such as counting when cooking. Similarly, to teach important skills that are critical for emergent literacy, parents are shown how to teach children to focus on the first sounds of words used around the house, and their corresponding letters. The Parent Facilitators provide parents with advice-reiterated in the Parent Activity Guide-on how to make activities easier or more challenging, depending on the child's level of development. In the weekly meetings, parents are also encouraged to share stories involving how their children interacted with the materials, and examine any important questions that might have emerged while working with the material at home. During workshops, parents practice math and literacy activities included in the next activity set and explore ways to adapt the activities to address individual learning styles.

1.3.3. Parent Facilitator Training. Prior to teaching the parents, the Parent Facilitators are provided with a detailed series of training activities to help trainers prepare parents to teach their children. Using active and participatory methods, this training includes a review of basic child development con-cepts with an emphasis on early math and literacy hands-on exploration of parents' and children's games and activities, and practice techniques for running effective parent group sessions.

1.3.4. Content of the Intervention: Literacy and Mathematics. Each of the nine units contains approximately ten activities, of which five focus on literacy and five focus on math. The content progression of GRS for each of the 9 units is summarized in Table 1.

Following the model originally constructed by Whitehurst and Lonigan [31], GRS targets emergent literacy through the development of both "outside-in" and "inside-out" skills. "Outside-in" skills represent children's understanding of the linguistic context and include the semantic and conceptual knowledge that comprises oral language, knowledge of narrative structure and narrativebuilding skills, and print conventions (e.g., left-to-right, front to back). "Inside-out" skills comprise children's knowledge of the rules for translating the particular writing they are trying to read into sounds and include knowledge of graphemes, phonological awareness, phoneme-grapheme correspondence, and emergent writing. Experience with "outside-in" skills fosters the development of oral language and vocabulary, whereas experience with "inside-out" skills fosters the development of early reading skills $[52,53]$. These emergent literacy goals and objectives by unit are summarized in Table 2.

In the area of mathematics, GRS follows the guidelines provided by the National Council of Teachers and Mathematics (NCTM) [46] for the acquisition of math concepts in the following areas: numbers and operations, geometry and spatial sense, measurement, algebra, and data analysis [45, 46]. To support the acquisition of these skills, educators have promoted five main processes: problem solving, reasoning, communicating, connecting, and representing [46]. GRS targets early math readiness through the development of these skills and processes, closely matching the math goals and objectives of NCTM (see Table 2).

Both literacy and math activities in GRS teach parents to use everyday interactions in the home and the community as the vehicles for learning. For instance, math activities include using familiar objects (e.g., buttons, laundry, cookware) to solve math problems, learning how math connects with real life (e.g., while cooking, during community walks or trips to the store), estimating numbers and sizes, and exploring shapes. Literacy activities involve learning through songs and poems, making up and telling stories, making books and reading together, building sight vocabulary, reading, drawing, and talking about ideas together, and exploring 
Table 1: Content Progression of the "Getting Ready for School" Intervention.

\begin{tabular}{|c|c|c|}
\hline & Literacy & Math \\
\hline Activity Set 1 & $\begin{array}{l}\text { Learn letters in their name, sounds associated with } \\
\text { those letters, and how to write their name. Words are } \\
\text { made up of groups of letters; letters represent sounds; } \\
\text { words begin with the letter on the left and ends with the } \\
\text { last letter on the right. Learn to recognize words to } \\
\text { familiar songs and poems. }\end{array}$ & $\begin{array}{l}\text { Understand that a number represents a set of objects; } \\
\text { practice counting, ordering, and comparing groups of } \\
\text { objects. Learn to count, write, identify, and represent } \\
\text { numbers } 1 \text { to } 5 \text {. }\end{array}$ \\
\hline Activity Set 2 & $\begin{array}{l}\text { Learn the sound associated with certain letters. } \\
\text { Emphasize the sound letters make as words are written. } \\
\text { Help children make sense of print by talking with them } \\
\text { while writing. Help children listen for and repeat the } \\
\text { initial sound in his/her name. }\end{array}$ & $\begin{array}{l}\text { Count a set of objects to } 10 \text { and identify the numerals } 1 \\
\text { through } 10 \text {. Sort groups of objects and practice } \\
\text { observing, describing, and making distinctions between } \\
\text { the characteristics of objects. Practice counting to } 10 \text {. }\end{array}$ \\
\hline Activity Set 3 & $\begin{array}{l}\text { Listen to and discuss family stories. Through } \\
\text { interesting discussions children will understand how } \\
\text { "stories" work. }\end{array}$ & $\begin{array}{l}\text { Order sets of objects and learn how to compare the } \\
\text { relative differences between them-longest to shortest, } \\
\text { lightest to darkest, more to less, lightest to heaviest. }\end{array}$ \\
\hline Activity Set 4 & $\begin{array}{l}\text { By conducting interviews children learn how to ask } \\
\text { questions to gather information. Use information to } \\
\text { create books and stories to share with family and } \\
\text { friends. }\end{array}$ & $\begin{array}{l}\text { Recognize, create, and extend patterns. Understand that } \\
\text { a pattern is a form of ordering that eventually repeats } \\
\text { itself. Make predictions about what happens next based } \\
\text { on an understanding of the pattern. }\end{array}$ \\
\hline Activity Set 5 & $\begin{array}{l}\text { Practice making letter-sound connections. Pronounce } \\
\text { words as they are written. Emphasize sounds at the } \\
\text { beginning, middle, and end of each word. }\end{array}$ & $\begin{array}{l}\text { Understand that geometry is the study of shapes and } \\
\text { spatial relationships. Provide children opportunities to } \\
\text { relate math to the real world by looking for and naming } \\
\text { different shapes. }\end{array}$ \\
\hline Activity Set 6 & $\begin{array}{l}\text { Understand all the reasons why we read and write. For } \\
\text { example, to remember information (make a list), } \\
\text { communicate information (write a letter), learn new } \\
\text { information (read a paper). }\end{array}$ & $\begin{array}{l}\text { Explore numbers one through } 20 \text {. Understand that the } \\
\text { number } 12 \text { is represented by one group of } 10 \text { plus } 2 \\
\text { ones, } 15 \text { is presented by one group of } 10 \text { plus } 5 \text { ones. }\end{array}$ \\
\hline Activity Set 7 & $\begin{array}{l}\text { Learn new words and understand how words are } \\
\text { organized into complete sentences. Learn to organize } \\
\text { thoughts and make themselves understood. Learn to } \\
\text { express their ideas and stories as well as understand the } \\
\text { ideas and stories of others. }\end{array}$ & $\begin{array}{l}\text { Add two sets of numbers together to get a total. Play } \\
\text { with sets of objects and counting to find the total } \\
\text { number. }\end{array}$ \\
\hline Activity Set 8 & $\begin{array}{l}\text { Recall events, retell stories, and speak in complete } \\
\text { sentences. Help children master prerequisites for } \\
\text { learning to read. }\end{array}$ & Practice adding to and taking away from sets of objects. \\
\hline Activity Set 9 & $\begin{array}{l}\text { Review all the skills learned during the previous } 8 \text { sets. } \\
\text { Think about and discuss how to identify and discuss } \\
\text { children's questions about Kindergarten. }\end{array}$ & $\begin{array}{l}\text { Review math activities from the previous eight sets. } \\
\text { Observe the ways children's approaches differ now from } \\
\text { when they did the task earlier. Make up number riddles } \\
\text { to challenge children to think about numbers one to } \\
\text { twenty. }\end{array}$ \\
\hline
\end{tabular}

sound-symbol relationships in everyday life. Each unit builds on the previous unit with content becoming increasingly more complex as the child moves from unit to unit.

1.4. Objectives of the Present Study. We conducted a mixedmethods study to obtain quantitative and qualitative information on the preliminary effectiveness and usability of the GRS intervention. Both quantitative and qualitative data addressed our primary objective: to assess whether the Getting Ready for School parent-focused intervention improves school-readiness skills. A small, quasi-experimental pilot study was conducted with a group of urban Latino preschool children participating in Head Start. We hypothesized that participation in the GRS curriculum would improve school readiness in literacy and math skills, relative to participation in business-as-usual Head Start. Additionally, qualitative data from parent focus groups addressed parental perceptions of children's improvements in these skills. Qualitative data also addressed our secondary objective: to assess parental perceptions of day-to-day use of the GRS intervention.

\section{Method}

2.1. Participants. Four classrooms in an urban Head Start program were targeted to participate in the study. Two classrooms were randomized to serve as the intervention classrooms, and two served as comparison classrooms. Randomization occurred at the classroom level in an attempt to reduce contamination between participants. Of the 56 children served by these classrooms who participated in this study, 
TABLE 2: Emergent literacy and math objectives by unit.

\begin{tabular}{|c|c|c|c|c|}
\hline & \multicolumn{3}{|c|}{ GRS Literacy Objectives } & GRS Activity Set \\
\hline \multirow{4}{*}{ "Outside-In Skills" } & \multicolumn{3}{|c|}{ Language-Semantic and conceptual knowledge } & $1,2,3,4,5,6,7,8,9$ \\
\hline & \multicolumn{3}{|c|}{ Narrative-Understanding and producing narrative } & $1,2,3,4,5,6,7,8,9$ \\
\hline & \multicolumn{3}{|c|}{ Conventions of print - Knowledge of standard print format } & $1,2,3,4,5,6,7,8,9$ \\
\hline & \multicolumn{3}{|l|}{ Emergent reading - Pretending to read } & $1,2,3,5,6,7,8,9$ \\
\hline \multirow{5}{*}{ "Inside-Out Skills" } & \multicolumn{3}{|c|}{ Knowledge of graphemes-letter name knowledge } & $1,2,3,4,5,6,7,8$ \\
\hline & \multicolumn{3}{|c|}{$\begin{array}{l}\text { Phonological awareness-detection of rhyme, manipulation of syllables, manipulation } \\
\text { of individual phonemes }\end{array}$} & $1,2,3,5,6,7,8$ \\
\hline & \multicolumn{3}{|c|}{ Syntactic awareness - repair grammatical errors } & 3 \\
\hline & \multicolumn{3}{|c|}{ Phoneme-grapheme correspondence-letter-sound knowledge, pseudoword decoding } & $1,2,3,4,5,6,7,8$ \\
\hline & \multicolumn{3}{|c|}{ Emergent writing-phonetic spelling } & $2,4,6,7,8,9$ \\
\hline & \multicolumn{3}{|c|}{ GRS Math Objectives } & GRS Activity Set \\
\hline & \multicolumn{3}{|l|}{ Numbers and operations } & $1,2,3,4,5,6,7,8,9$ \\
\hline & \multicolumn{3}{|l|}{ Geometry and spatial sense } & $4,5,9$ \\
\hline & \multicolumn{3}{|l|}{ Measurement } & $1,2,3,4,5,6,7,9$ \\
\hline & \multicolumn{3}{|l|}{ Algebra } & $1,2,3,4,5,6,7,8,9$ \\
\hline & \multicolumn{3}{|l|}{ Data analysis } & $1,2,3,4,5,6,7,8,9$ \\
\hline \multicolumn{5}{|c|}{ TABLE 3: Demographics by group. } \\
\hline \multirow{2}{*}{\multicolumn{2}{|c|}{ Mean age in months at pretest (SD) }} & $\begin{array}{l}\text { Intervention } \\
\quad(n=26)\end{array}$ & $\begin{array}{l}\text { Comparison } \\
\quad(n=30)\end{array}$ & $P$ \\
\hline & & $46.9(6.2)$ & $45.6(7.1)$ & 0.48 \\
\hline \multirow{3}{*}{ Ethnicity (\%) } & Hispanic or Latino & $25(96 \%)$ & $28(93 \%)$ & \multirow{3}{*}{0.24} \\
\hline & Asian & 0 & $2(7 \%)$ & \\
\hline & Other & $1(4 \%)$ & 0 & \\
\hline \multirow{3}{*}{$\begin{array}{l}\text { Primary language spoken at } \\
\text { home }(\%)\end{array}$} & Spanish & $25(96 \%)$ & $26(87 \%)$ & \multirow{3}{*}{0.19} \\
\hline & English & 0 & $3(10 \%)$ & \\
\hline & Other & $1(4 \%)$ & $1(3 \%)$ & \\
\hline \multirow{6}{*}{ Maternal education (\%) } & Less than high school & & & \multirow{6}{*}{0.32} \\
\hline & GED or high school & $\begin{array}{c}14(54 \%) \\
3(12 \%)\end{array}$ & $\begin{array}{l}12(40 \%) \\
9(30 \%)\end{array}$ & \\
\hline & Some postsecondary & $1(4 \%)$ & $4(13 \%)$ & \\
\hline & $\begin{array}{c}\text { school } \\
\text { Associate deoree }\end{array}$ & $1(4 \%)$ & $1(3 \%)$ & \\
\hline & Associate degree & $5(19 \%)$ & $3(10 \%)$ & \\
\hline & $\begin{array}{l}\text { BS or advanced degree } \\
\text { Other/did not respond }\end{array}$ & & & \\
\hline
\end{tabular}

There were no significant demographic differences between groups.

26 were in the GRS intervention classrooms, and 30 participated in Head Start-as-usual classrooms.

Children were 3 to 4 years old at the start of the study (mean age at pretest $=46.2$ months, s.d. 6.7). Demographic information was obtained from Head Start records. Ninetyfive percent of all participants self-identified as Hispanic or Latino, 91\% spoke primarily Spanish at home, and 70\% of parents had a high school education or less. Table 3 shows that there were no demographic differences between groups.

Fifty-six children provided pretest data, before the start of the intervention. There were 7 children ( 1 intervention, 6 comparison) from whom posttest data were not available following completion of the intervention. Of these children, 4 were no longer in the Head Start program and 3 (including the 1 intervention child) did not attend posttest assessments.
These children did not significantly differ in terms of age, ethnicity, language spoken at home, or parent education from the remaining children (all $P$ 's $>0.6$ ). The remaining 49 children on whom both pre- and posttest data are available constitute the participants in the analyses below.

2.2. Materials and Procedure. The GRS intervention was implemented in an urban Head Start program in Northern Manhattan in sequential Spring and Fall semesters. Prior to the present study, the program had previously implemented GRS in one classroom per semester for two years. This Head Start program operates as a combination model where children and their parents/caregivers participate in biweekly 3.5-hour classroom experiences and receive a monthly 
home visit. While children are in the preschool classroom, parents/caregivers participate in various educational and vocational workshops. At the time of the study, two GRSnaïve classrooms were randomly selected to receive the GRS intervention. Two additional GRS-naïve classrooms in the Head Start program were randomly selected as comparison groups and offered the intervention at a later date.

Before the GRS implementation began, all parents in the intervention and comparison classrooms were informed of the procedures of the study and were invited to allow their children to participate in the collection of behavioral data before and after the study. GRS was implemented at the classroom level regardless of parents' consent to participate in the study. Additionally, parents in the intervention classrooms were invited to attend a focus group following completion of the study. Informed consent was obtained according to the policies of the Columbia University Institutional Review Board.

2.2.1. Facilitator Training. Parents from both intervention classrooms received workshops led by a bilingual, bicultural Parent Facilitator who had previously been trained by the curriculum developer following the activities in the Trainthe-Trainer Manual.

2.2.2. Parent Workshops. Families in the GRS intervention group participated in a weekly 2-hour workshop for 15 weeks focusing on promoting young children's school-readiness skills in reading and math. A trained, bilingual, bicultural facilitator led the parent workshops according to lessons in the Parent Facilitator Guide.

2.2.3. Child Cognitive Testing. Prior to the start of the intervention, participating children from both the intervention and comparison groups were pulled out of their regular classroom by a bilingual, trained research assistant for 2030 minutes to participate in a brief assessment of early literacy, oral language, and early mathematics skills. This procedure was repeated at the end of the intervention period, approximately 5 months after the pretest (mean $=157$ days between testing sessions, s.d. 15 days, with no difference in latency between groups $(t(46)=-1.71 ; P=0.1)$. Children's language dominance was established by classroom teacher reports based on teacher's ongoing language assessment conducted in the Head Start program using the Work Sampling System method. Children were tested in their dominant language accordingly.

Language and Emergent Literacy Skills were tested using the following subtests from the Woodcock-Johnson Test of Academic Achievement (WJ III)/Batería III WoodcockMuñoz [54]: Letter-Word Identification, Passage Comprehension, Understanding Directions, and Picture Vocabulary Subscales. The Letter-Word Identification test involves asking the child to identify printed letters and later to read printed words aloud. The Understanding Directions subtest tests measures of oral language comprehension by asking the child to follow increasingly commands of increasing linguistic complexity. The Spelling subtest assesses children's ability to print letters and words. The Picture Vocabulary subtest assesses oral language and lexical knowledge.

Math Skills were tested using the Applied Problems and Quantitative Concepts Subscales of the WJIII/Bateria Woodcock-Munoz. Applied Problems measures the child's ability to analyze and solve math problems. Initial items involve counting and identifying the number of objects in a picture, progressing to more complex calculations. Quantitative Concepts measures knowledge of mathematical concepts, including counting, identifying numbers, shapes, and sequences.

2.2.4. Parent Focus Groups. At the end of the intervention session, parents were invited to participate in a focus group to share their experiences with the GRS curriculum. Grounded theory [55] guided the design and analysis of focus groups. The aim was to generate a general explanation/description of the perceived effectiveness and user-friendliness of the intervention based on the views and opinions of participating parents. While our quantitative analyses were hypothesis driven, we used an inductive approach to analyze data from focus groups, responding to two general research questions: (1) What are families' perceptions of the efficacy of the intervention and how well it works? And (2) what are families' perceptions of the day-to-day use of the GRS intervention? [56].

Following Strauss and Corbin's analytic procedures [57], focus group data were transcribed and later analyzed using open and selective coding [57]. During open coding, data were broken into categories representing emergent themes about the GRS intervention. Selective coding was utilized to determine core categories and describe relationships among the categories.

\section{Results}

To test the short-term impact of the GRS intervention in this small pilot study, several analyses were conducted. First, scores on standardized tests of language, emergent literacy, and math skills were analyzed to determine whether participation in the intervention led to increased improvement over time, relative to business-as-usual Head Start. Second, data from focus groups were analyzed to understand parents' responses to the GRS intervention, including their initial perceptions of its effectiveness and user-friendliness.

3.1. Literacy and Math Testing. Means and standard deviations of raw scores on each task for children in the intervention and comparison groups are shown in Table 4. At pretest, one child in the intervention group did not complete the Spelling subtest, and one child in the comparison group did not complete the Picture Vocabulary or Quantitative Concepts subtest. All children remaining at the study at the time of the posttest completed all subtests.

There were no significant differences between groups in any of the pretest scores (independent samples $t$-tests; all $P$ 's $>0.1$ ). In all the following analyses, raw scores are used, with age in months entered as a covariate. 
TABLE 4: Language and math performance by group, before and after the intervention period ${ }^{\mathrm{a}}$.

\begin{tabular}{|c|c|c|c|c|c|c|c|}
\hline \multirow{2}{*}{ Subtest } & \multirow{2}{*}{ Time } & \multicolumn{3}{|c|}{ Intervention } & \multicolumn{3}{|c|}{ Comparison } \\
\hline & & $N$ & Mean & Standard Deviation & $N$ & Mean & Standard Deviation \\
\hline \multirow{2}{*}{$\begin{array}{l}\text { Letter-word } \\
\text { identification }\end{array}$} & Pre & 26 & 3.8 & 2.9 & 30 & 3.8 & 3.2 \\
\hline & Post & 25 & 6.4 & 3.7 & 24 & 5.6 & 4.0 \\
\hline \multirow{2}{*}{$\begin{array}{l}\text { Understanding } \\
\text { directions }\end{array}$} & Pre & 26 & 7.4 & 3.8 & 30 & 6.6 & 2.9 \\
\hline & Post & 25 & 11.0 & 5.9 & 24 & 10.2 & 4.4 \\
\hline \multirow{2}{*}{ Spelling } & Pre & 25 & 4.2 & 2.4 & 30 & 3.4 & 2.2 \\
\hline & Post & 25 & 7.2 & 3.0 & 24 & 5.6 & 2.1 \\
\hline \multirow{2}{*}{ Applied problems } & Pre & 26 & 6.8 & 3.2 & 30 & 6.5 & 3.3 \\
\hline & Post & 25 & 10.5 & 3.9 & 24 & 8.3 & 4.0 \\
\hline \multirow{2}{*}{ Picture vocabulary } & Pre & 26 & 13.5 & 4.4 & 29 & 12.1 & 3.6 \\
\hline & Post & 25 & 15.8 & 3.2 & 24 & 13.7 & 3.7 \\
\hline \multirow{2}{*}{ Quantitative concepts } & Pre & 26 & 5.1 & 2.6 & 29 & 4.2 & 2.1 \\
\hline & Post & 25 & 6.9 & 2.2 & 24 & 6.2 & 2.0 \\
\hline
\end{tabular}

a Means and standard deviations of raw scores for each task for the intervention and comparison groups. There were no significant differences between groups in any of the pretest scores (all $P$ 's $>0.1$ ).

TABle 5: Multivariate General Linear Model showing the hypothesized overall time $*$ group interaction ${ }^{\mathrm{a}}$.

\begin{tabular}{|c|c|c|c|c|}
\hline Effect & & $F$ & Partial Eta squared & Sig. \\
\hline \multirow{3}{*}{ Between subjects } & Intercept & 5.600 & 0.463 & 0.000 \\
\hline & Age & 17.056 & 0.724 & 0.000 \\
\hline & Group (GRS versus Comparison) & 1.409 & 0.178 & 0.236 \\
\hline \multirow{3}{*}{ Within subjects } & Time (pre versus post) & 2.055 & 0.240 & 0.081 \\
\hline & Time $*$ age & 1.518 & 0.189 & 0.198 \\
\hline & Time $*$ group & 2.515 & 0.279 & 0.037 \\
\hline
\end{tabular}

${ }^{a}$ To test the hypothesis that children whose parents received the GRS intervention would improve more over time relative to children whose parents received business-as-usual involvement at Head Start, a multivariate repeated measures General Linear Model was run, with scores on all six pre- and posttests entered as the dependent variables, with time entered as the within-group variable (2 levels: pre and post), with intervention group entered as the between-group variable (2 levels: intervention and comparison), and with age at pretest entered as a covariate. As predicted, a significant time $*$ group interaction was found, suggesting that, overall, children in the intervention group improved more than children in the comparison group $(F(6,39)=2.5 ; P<0.037)$.

To test the hypothesis that children whose parents received the GRS intervention would improve more over time relative to children whose parents received business-as-usual involvement at Head Start, a multivariate repeated measures General Linear Model (GLM) was performed, with time as the within-group variable (2 levels: pre and post), intervention as the between-group variable ( 2 levels: intervention and comparison), and age in months at pretest entered as a covariate. As would be expected, there was a main effect on raw score of age at pretest $(F(6,39)=17.1 ; P<.000)$. There was no main effect of time or group. However, as predicted, a significant time $*$ group interaction was found $(F(6,39)=$ 2.5; $P<0.037)$, confirming that Head Start children whose parents received GRS showed more overall growth in skills relative to children who were enrolled in Head Start-as-usual (see Table 5).

Pos thoc tests of individual subtests revealed that Applied Problems demonstrated a significant time $*$ group interaction $(F(1,46)=5.9 ; P<0.019)$, such that the intervention group improved significantly more than the comparison group (see Table 6). Additionally, Figure 1 illustrates that the change from pretest to posttest is in the predicted direction for most subtests, with a more positive slope in the intervention group in four out of the six tests. Thus, preliminary short-term evidence from a small sample suggests that GRS may improvecertain school-readiness skills over and above a Head Start-as-usual experience.

3.2. Focus Groups. Based on grounded theory [55], focus groups elicited open-ended responses from families in response to their participation in the intervention. Qualitative data were assessed according to our two study objectives: (1) our primary objective of assessing GRS' effectiveness and (2) our secondary objective of assessing parents' impressions of day-to-day usability of the GRS intervention. Regarding the first objective, parents reported positive gains in children's literacy and mathematics skills. In addition, the central and most prevalent theme related to the effectiveness of the intervention was parents' report of "learning about learning," providing a preliminary hypothesis about a possible mechanism of change. Regarding the second objective, several themes emerged, as summarized in the following. 
TABLe 6: General Linear Models for Individual Literacy and Math Subtests ${ }^{\mathrm{a}}$.

\begin{tabular}{|c|c|c|c|}
\hline Subtest & Factor & $F$ & Sig \\
\hline \multirow{5}{*}{ Letter-Word ID } & Time (Pre versus Post) & 0.079 & 0.780 \\
\hline & Group (Intervention versus Comparison) & 0.038 & 0.846 \\
\hline & Age at Pretest & 1.725 & 0.196 \\
\hline & Time $*$ Age & 0.237 & 0.629 \\
\hline & Time $*$ Group & 1.072 & 0.306 \\
\hline \multirow{5}{*}{ Understanding Directions } & Time (Pre versus Post) & 0.106 & 0.746 \\
\hline & Group (Intervention versus Comparison) & 0.300 & 0.587 \\
\hline & Age at Pretest & 7.104 & 0.011 \\
\hline & Time $*$ Age & 0.175 & 0.678 \\
\hline & Time $*$ Group & 0.005 & 0.947 \\
\hline \multirow{5}{*}{ Spelling } & Time (Pre versus Post) & 1.501 & 0.227 \\
\hline & Group (Intervention versus Comparison) & 4.103 & 0.049 \\
\hline & Age at Pretest & 17.503 & 0.000 \\
\hline & Time $*$ Age & 0.010 & 0.919 \\
\hline & Time $*$ Group & 2.400 & 0.128 \\
\hline \multirow{5}{*}{ Applied Problems } & Time (Pre versus Post) & 0.304 & 0.584 \\
\hline & Group (Intervention versus Comparison) & 1.129 & 0.294 \\
\hline & Age at Pretest & 44.827 & 0.000 \\
\hline & Time $*$ Age & 3.100 & 0.085 \\
\hline & Time $*$ Group & 5.915 & 0.019 \\
\hline \multirow{5}{*}{ Picture Vocabulary } & Time (Pre versus Post) & 1.828 & 0.183 \\
\hline & Group (Intervention versus Comparison) & 3.535 & 0.067 \\
\hline & Age at Pretest & 35.075 & 0.000 \\
\hline & Time $*$ Age & 0.792 & 0.378 \\
\hline & Time $*$ Group & 0.834 & 0.366 \\
\hline \multirow{5}{*}{ Quantitative Concepts } & Time (Pre versus Post) & 5.856 & 0.020 \\
\hline & Group (Intervention versus Comparison) & 2.395 & 0.129 \\
\hline & Age at Pretest & 27.063 & 0.000 \\
\hline & Time $*$ Age & 2.041 & 0.160 \\
\hline & Time $*$ Group & 0.734 & 0.396 \\
\hline
\end{tabular}

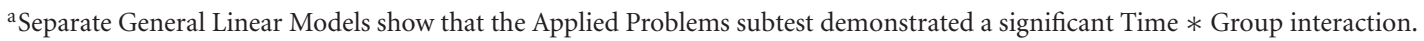

Primary Aim: Effectiveness of the GRS Intervention

3.2.1. Perceived Effectiveness of the GRS Intervention. Overwhelmingly parents reported seeing positive changes in their children's literacy and math skills in response to their participation in the GRS intervention. Parents explained changes they saw in their children's skills and attitudes towards learning. In their own words,

The program introduced him to math, reading, writing... it took him to another level. This is going to help him in the future, in school.

I think he learned most about math: numbers, shapes, sorting. He learned about letters too but the math was really new.

I see much change in her enthusiasm. She wants to do work, she initiates it and seems to have develop a habit of wanting to read, write, draw...
She asks me to read to her more often. She is always saying "please read again!"

3.2.2. Learning about Learning. The most persistent theme in focus groups was parents' notion that GRS taught them about how to teach/support their children's learning. Parents frequently discussed an increased focus on valuing children's process versus outcomes, asking open-ended questions, engaging children in conversation, problem-solving activities, and learning to be patient with children and to follow their pace as they made progress. This theme may represent a potential mechanism of change underlying the improvements observed in overall school-readiness skills among the children participating in the intervention. Representative comments include the following:

Whenever my son made a picture, I used to always ask him "what is it?" and he usually did not say anything. Now I ask him to tell me about his 


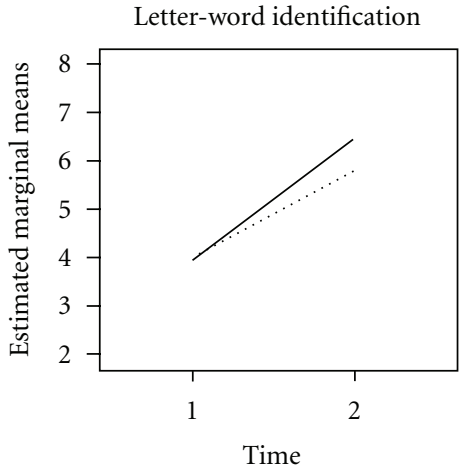

(a)

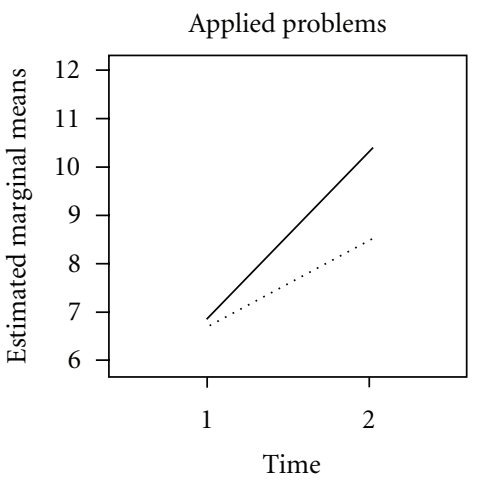

Group

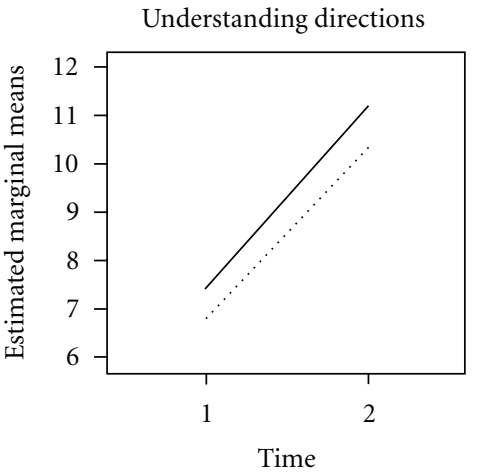

(b)

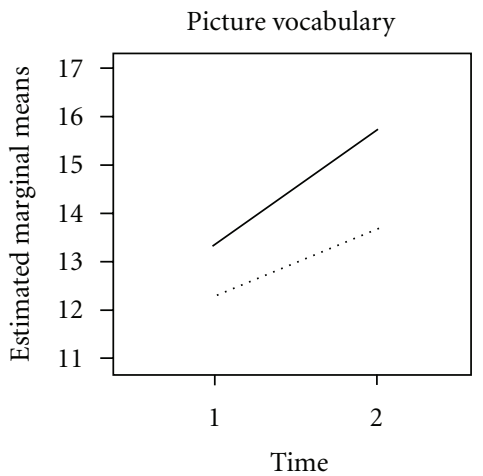

Group

-.... Intervention

(e)

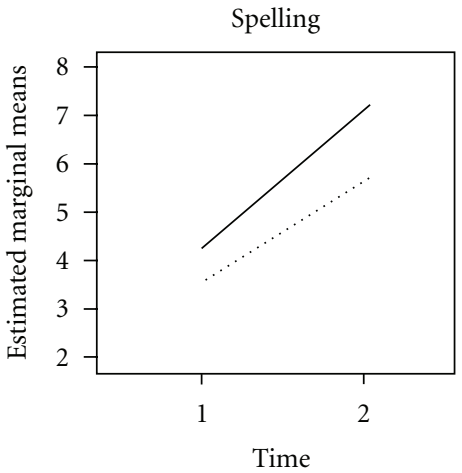

(c)

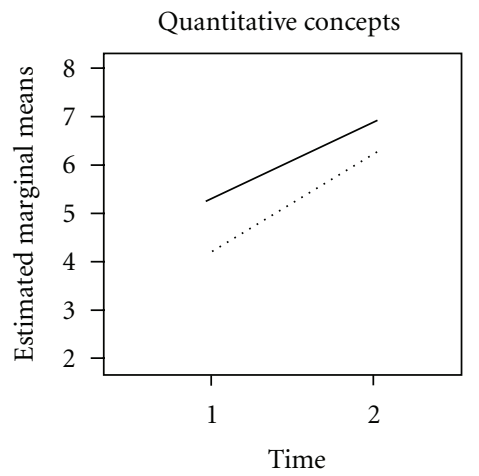

Group

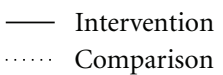

(f)

FIGURE 1: Language and math performance over time by group. The direction of the interaction is in the predicted direction for most subtests, with a more positive slope in the intervention group in four out of the six tests. (Note that the scale is the same for all subtests, but the intercept varies according to the range of raw scores.) This provides preliminary short-term evidence from a small sample to suggest that GRS may lead to improvement in some of children's school-readiness skills over and above a Head Start-as-usual experience.

picture, the colors, the shapes and we have much longer conversations.

I really learned how to organize myself and be more patient in working with my daughter. When we are reading a story, I know what to ask her and now she asks those questions herself. I feel like reading is the base of everything. The book we got had many elements to help us read to our children, reading and understanding reading. That was excellent.

We are our children's first teachers and these tools really helped me know how to prepare him for school.

Secondary Aim: General response to use of the GRS intervention.

3.2.3. Need for Parent/Teacher Coordinated Efforts. Parents consistently requested that the classroom teachers should engage in similar activities in the classroom. Parents wanted playful learning for their children that focused on the same literacy and math areas targeted in the GRS curriculum. Parents reported that having a coordinated effort between them and the teachers would improve their children's outcomes and also help them provide continuity of experiences in the home. In their own words,

I think we should also give this book to the classroom teachers. They spend many hours with our children and... this way we would be doubly beneficial for the children and for us too, the teachers can help us keep our minds a little more open about education.

I am a substitute teacher, as well as a parent. For me the book was very useful, not just with my daughter but in my classroom. I took many ideas from the book and it really helped me as a teacher. For example, I never really focused on mathemat$i c s$, other than counting, I did not know what else to do... now I have many ideas. 
3.2.4. Making the Time. Parents were asked to work with their children on a daily basis. They talked about how challenging it was to make time when they are busy with work, other children, housework, and so forth. However, there was an overwhelming desire expressed by families to "make the time." Parents described how a little bit of time was all that was necessary and that children would frequently continue to be engaged in games or activities after parents had moved to other tasks. They also described realizing how sometimes one need not make explicit time, but rather just include the child in daily activities as these can serve as learning experiences as well.

There never is enough time... one has to learn what their priorities are. If your child is your priority, then you find the time.

I did not know that my son could help me cook and that if he did, maybe I could teach him to count, measure... He loves being my helper.

3.2.5. Involving Other Family Members. Parents described how part of making the time was also including other family members, predominantly spouses and older children. Busy lives made some parents ask other parents or older children to join in the GRS activities. Some mothers described the GRS book as a tool to explain to the child's father the kind of learning that was taking place in school.

I had to involve my husband. After he comes home from work and has a rest, I ask him to spend some time doing activities with our girl. This way he also joins us. When he gets home, my girl says "mami, papi...let us go do work!"

I shared the materials with my cousin who lives in Queens. Her children do not go to any Head Start or any program so she is very interested in what I give her. I see her every weekend and pass on the materials from the class.

3.2.6. Challenges. Families described some difficulty working with their children on the curriculum calendars. In particular, it was difficult to explain the concept of time to preschoolers. Other games, especially some of those related to math skills, were difficult to implement since parents themselves had little experience with them (e.g., Dominos). They also requested more strategies to help their children sustain attention during tasks and manage challenging behaviors that took place while engaged in the materials.

I also want to learn some specific ways to help him pay more attention and persist when things that he has to do are difficult. I think he has made some progress but I would like more ideas.

3.2.7. Packaging of Materials. Families reported positive impressions of the packaging of the materials. They described their children responding positively to the pictures, the games and the backpack.
For Thanksgiving, we all went around the table saying what we are grateful for. When it was my son's turn, he said "I am thankful for my school backpack with games."

I like that all the pictures are in black and white because after we played a game or talked about a picture, we would spend time coloring it. We have put some of those pictures in her room now, as decorations.

\section{Discussion}

The primary objective of this study was to assess whether a parent-focused school-readiness intervention would have an effect on the early math and literacy skills of low-income children of predominantly Latino descent. In addition, we aimed to explore parents' perceptions of the effectiveness of the intervention, as well as parental responses to the dayto-day usability of the materials. The preliminary results presented previously suggest that a targeted intervention that actively involves parents has the potential to improve children's school-readiness skills over and above a Head Startas-usual experience. Further, qualitative data obtained from focus groups highlight the overwhelmingly positive response of parents to the materials. In addition, the qualitative data point to a possible mechanism for the change observed in the quantitative study. Overwhelmingly, parents talked about learning about how their children learn and acquiring skills and tools to facilitate children's learning. Together, these results highlight the important role that parent-based, targeted interventions can have in the emergent schoolreadiness skills of preschool children.

Evidence-based interventions can improve the degree to which disadvantaged children are ready for school and in turn can have long-lasting ramifications for educational and life achievement. However, individual programs typically only report modest gains [22]. As parents and teachers independently influence school readiness [23], one promising approach to narrowing the gap in school readiness may be to harness the power of parents to reinforce the critical skills taught in school, thereby providing support for these two independent sources of learning. Indeed, programs targeting both parents and teachers have increased potential to affect outcomes $[12,58,59]$.

This study thus provides some support to bioecological theory, which suggests that human development requires "proximal processes," or progressively complex reciprocal interactions between children and people in their immediate environment [26-28]. To the extent that parentchild interactions represent the most proximal-and thus most powerful-processes in children's lives, one would expect that interventions aimed at directly altering these processes may wield particularly strong effects on child development. Indeed, Bronfenbrenner [25] postulated that the family may be the most effective and economical system for fostering and sustaining early child development. He further stated that interventions targeted directly at parents tend to be particularly effective, as they may serve as 
a catalyst for sustaining and enhancing the effects of classroom intervention [25]. In the context of the preliminary results presented here, we may theorize that GRS may directly affect parenting, which in turn may amplify the effects of classroom literacy and math pedagogy.

Socioeconomically disadvantaged Latino children are at particular risk for poor school readiness [16-18] and yet remain an under-studied and underserved group. The GRS materials are available in both English and Spanish, require only a minimal parent literacy level, and in the present study were administered by a fully bilingual, bicultural team. Qualitative data obtained from focus groups suggest that parents enjoyed and felt comfortable with the materials. More detailed examination of the cross-cultural relevance of the program is warranted prior to wider dissemination of the materials.

4.1. Limitations of the Present Study. This pilot study evaluated the potential of the Getting Ready for School intervention to improve disadvantaged preschooler's early literacy and math skills. Though potentially promising, the study's small sample size renders these results preliminary. Further research must be conducted with larger groups of children and parents to fully assess the feasibility and efficacy of this intervention.

Randomization of the intervention occurred at the classroom level, rather than at the family level, to reduce contamination between the intervention and comparison groups. The lack of randomization at the family level was mitigated in part by the fact that intervention and comparison families did not differ on key demographic factors. Nonetheless, future research using a design randomized at the family level will be necessary for rigorously testing the efficacy of the program.

In addition, the data collected here have a nested structure, with families nested in classrooms. Although multilevel models would not have had sufficient power to detect treatment effects in this small pilot study, future work with a larger sample will have the power to fully consider and investigate the nested structure of the data.

The present study sample consisted nearly entirely of disadvantaged Latino preschoolers and their mothers. Further work should be conducted with a diverse population to assess the generalizability of the intervention with other socioeconomic and ethnic groups.

This study did not measure the fidelity of implementation of the GRS intervention. The results of this study would suggest that parents engaged in literacy- and mathpromoting activities at home, but we are uncertain of the specific activities or processes they used. Measuring fidelity of implementation at the home level might also shed some light over the mechanisms of change for this intervention as well as allow for comparison between groups of parents who had low and high adherence to curriculum guidelines.

4.2. Future Directions. While the current implementation of GRS focuses exclusively on parents, future work will attempt to more fully integrate the GRS curriculum for use by both parents and teachers. By supporting classroom and home learning experiences in parallel, we may take advantage of these independent sources of variance, leading to an additive benefit $[5,12,60]$. This idea was often articulated by parents during focus groups who wanted their children's classroom teachers to "support the same work they were doing." Additional research on the additive effects of interventions that place equal weight on parent and classroom practices will be important in understanding the mechanisms by which interventions exert positive effects.

Additionally, the current implementation of GRS is focused on improving literacy and math readiness. While an evidence-based focus on these skills is critical, recent research highlights the complementary importance of early self-regulation skills [61-63]. Accumulating evidence suggests that both cognitive and self-regulation skills are independently important for academic success [64]. Additionally, focus groups with GRS parents noted the need for skill building to help maintain children's "attention to activities" and "reduce frustration when faced with challenges." Thus, the addition of a self-regulation component might strengthen the curriculum. In fact, several recent investigations have revealed that preschool programs focused jointly on self-regulation and other aspects of school readiness can be effective [65-69].

Finally, future research should consider additional factors and pathways that may contribute to the acquisition of literacy and math in the home, such as the availability of materials and exposure to educational programs/practices. While there is no evidence to suggest that differences in these areas were present between the intervention and the comparison classrooms in the present study, these factors may mediate or interact with school-readiness interventions in important ways.

\section{Conclusions}

The results of this preliminary study demonstrate that a targeted parent-focused program may be effective in supporting the development of school-readiness skills of disadvantaged preschool children. However, early childhood programs need the funding and guidance necessary to implement the kinds of interventions that will maximize parents' involvement in their children's learning. Assistance needs to be provided to Head Start programs in identifying and implementing evidence-based interventions to help build the skills of parents in supporting children's school readiness. In addition, significant professional development is needed to help staff develop the necessary skills to help parents support children's learning. Further research is necessary to understand how to best accomplish this goal. It is not just what materials we share with parents but how those materials are presented that maximizes the likelihood of feasibility, fidelity of implementation, and positive learning outcomes for children. We also must strive to understand how these programs intersect with existing cultural practices, the home learning environment, and the larger community. 


\section{Authors' Contributions}

Kimberly G. Noble and Helena Duch contributed equally to this work.

\section{Acknowledgment}

The authors gratefully acknowledge the help of Maria Gonzalez, Katherine Mora, the families and children who participated, and the generous funding of the Farber Foundation. The authors thank the Open Society Foundation for their support in the initial development and implementation of the Getting Ready for School initiative.

\section{References}

[1] Task Force on Community Preventive Services, "Promoting health through the social environment: early childhood development programs," in Guide to Community Preventive Services, 2010.

[2] R. H. Bradley, R. F. Corwyn, H. P. McAdoo, and C. García Coll, "The home environments of children in the United States Part I: variations by age, ethnicity, and poverty status," Child Development, vol. 72, no. 6, pp. 1844-1867, 2001.

[3] K. G. Noble, M. F. Norman, and M. J. Farah, "Neurocognitive correlates of socioeconomic status in kindergarten children," Developmental Science, vol. 8, no. 1, pp. 74-87, 2005.

[4] K. G. Noble, B. D. McCandliss, and M. J. Farah, "Socioeconomic gradients predict individual differences in neurocognitive abilities," Developmental Science, vol. 10, no. 4, pp. 464480, 2007.

[5] G. J. Whitehurst, "Language processes in context: language learning in children reared in poverty," in Research on Communication and Language Disorders: Contribution to Theories of Language Development, L. B. Adamson and M. A. Romski, Eds., pp. 233-266, Brookes Publishing, Baltimore, Md, USA, 1997.

[6] A. W. Gottfried, A. E. Gottfried, K. Bathurst, D. W. Guerin, and M. M. Parramore, "Socioeconomic status in children's development and family environment: infancy through adolescence," in Socioeconomic Status, Parenting and Child Development, M. H. Bornstein and R. H. Bradley, Eds., pp. 189-207, Lawrence Erlbaum Associates, Mahwah, NJ, USA, 2003.

[7] S. E. Rimm-Kaufman, R. C. Pianta, and M. J. Cox, "Teachers' judgments of problems in the transition to kindergarten," Early Childhood Research Quarterly, vol. 15, no. 2, pp. 147-166, 2000.

[8] C. Rouse, J. Brooks-Gunn, and S. McLanahan, "Introducing the issue. School readiness: closing racial and ethnic gaps," Future of Children, vol. 15, no. 1, pp. 3-14, 2005.

[9] P. C. High and Committee on Early Childhood Adoption and Dependent Care and Council on School Health, "School readiness," Pediatrics, vol. 121, pp. e1008-e1015, 2008.

[10] J. West, K. Denton, and E. Germino-Hausken, America's Kindergartener's: Findings from the Early Childhood Longitudinal Study, Kindergarten Class of 1998-99, National Center for Education Statistics, Washington, DC, USA, 2001.

[11] L. Feinstein, "Inequality in the early cognitive development of British children in the 1970 cohort," Economica, vol. 70, no. 277, pp. 73-97, 2003.
[12] J. Brooks-Gunn and L. B. Markman, "The contribution of parenting to ethnic and racial gaps in school readiness," Future of Children, vol. 15, no. 1, pp. 139-168, 2005.

[13] J. Brooks-Gunn, "Do you believe in magic? What can we expect from early childhood intervention programs?" Social Policy Report of the Society for Research in Child Development, vol. 17, no. 1, pp. 3-14, 2003.

[14] J. Bennett, Investment in Population Health in Five OECD Countries, Organization for Economic Cooperation and Development, Paris, France, 2003.

[15] N. Baydar, J. Brooks-Gunn, and F. F. Furstenberg, "Early warning signs of functional illiteracy: predictors in childhood and adolescence," Child Development, vol. 64, no. 3, pp. 815-829, 1993.

[16] C. Galindo and B. Fuller, "The social competence of Latino kindergartners and growth in mathematical understanding," Developmental Psychology, vol. 46, no. 3, pp. 579-592, 2010.

[17] M. Quirk, M. Furlong, E. Lilles, E. Felix, and J. Chin, "Preliminary development of a kindergarten school readiness assessment for Latino students," Journal of Applied School Psychology, vol. 27, no. 1, pp. 77-102, 2011.

[18] J. Brooks-Gunn and L. B. Markman, "The contribution of parenting to ethnic and racial gaps in school readiness," Future of Children, vol. 15, no. 1, pp. 139-168, 2005.

[19] M. Berends and R. V. Penaloza, "Increasing racial isolation and test score gaps in mathematics: a 30-year perspective," Teachers College Record, vol. 112, no. 4, pp. 978-1007, 2010.

[20] K. A. Magnuson and J. Waldfogel, "Early childhood care and education: effects on ethnic and racial gaps in school readiness," Future of Children, vol. 15, no. 1, pp. 169-196, 2005.

[21] L. M. Anderson, C. Shinn, M. T. Fullilove et al., "The effectiveness of early childhood development programs: a systematic review," American Journal of Preventive Medicine, vol. 24, supplement 3, pp. 32-46, 2003.

[22] G. D. Borman, G. M. Hewes, L. T. Overman, and S. Brown, "Comprehensive school reform and achievement: a metaanalysis," Review of Educational Research, vol. 73, no. 2, pp. 125-230, 2003.

[23] U. Bronfenbrenner, "Making human beings human: bioecological perspectives on human development," in Making Human Beings Human: Bioecological Perspectives on Human Development xxix, p. 306, Sage Publications, Thousand Oaks, Calif, USA, 2005.

[24] M. Burchinal, J. E. Roberts, S. A. Zeisel, E. A. Hennon, and S. Hooper, "Social risk and protective child, parenting, and child care factors in early elementary school years," Parenting: Science and Practice, vol. 6, no. 1, pp. 79-113, 2006.

[25] U. Bronfenbrenner, "Is early intervention effective?" Early Childhood Education Journal, vol. 2, no. 2, pp. 14-18, 1974.

[26] U. Bronfenbrenner and S. J. Ceci, "Nature-nurture reconceptualized in developmental perspective: a bioecological model," Psychological Review, vol. 101, no. 4, pp. 568-586, 1994.

[27] U. Bronfenbrenner and G. W. Evans, "Developmental science in the 21st century: emerging questions, theoretical models, research designs and empirical findings," Social Development, vol. 9, no. 1, pp. 115-125, 2000.

[28] J. R. H. Tudge, I. Mokrova, B. E. Hatfield, and R. B. Karnik, "Uses and misuses of Bronfenbrenner's bioecological theory of human development," Journal of Family Theory \& Review, vol. 1, no. 4, pp. 198-210, 2009.

[29] M. A. Evans and D. Shaw, "Home grown for reading: parental contributions to young children's emergent literacy and word recognition," Canadian Psychology, vol. 49, no. 2, pp. 89-95, 2008. 
[30] S. R. Hooper, J. E. Roberts, L. Nelson, S. Zeisel, and D. K. Fannin, "Preschool predictors of narrative writing skills in elementary school children," School Psychology Quarterly, vol. 25, no. 1, pp. 1-12, 2010.

[31] G. J. Whitehurst and C. J. Lonigan, "Child development and emergent literacy," Child Development, vol. 69, no. 3, pp. 848 872, 1998.

[32] G. J. Whitehurst, J. N. Epstein, A. Angell, A. C. Payne, D. Crone, and J. E. Fischel, "Outcomes of an emergent literacy intervention in head start," Journal of Educational Psychology, vol. 86, no. 4, pp. 542-555, 1994.

[33] G. J. Whitehurst, D. S. Arnold, J. N. Epstein, A. L. Angell, M. Smith, and J. E. Fischel, "A Picture book reading intervention in day care and home for children from low-income families," Developmental Psychology, vol. 30, no. 5, pp. 679-689, 1994.

[34] M. Senechal, "Testing the home literacy model: parent involvement in kindergarten is differentially related to grade 4 reading comprehension, fluency, spelling, and reading for pleasure," Scientific Studies of Reading, vol. 10, no. 1, pp. 59-87, 2006.

[35] M. Senechal and J. A. LeFevre, "Parental involvement in the development of children's reading skill: a five-year longitudinal study," Child Development, vol. 73, no. 2, pp. 445-460, 2002.

[36] B. A. Levy, Z. Gong, S. Hessels, M. A. Evans, and D. Jared, "Understanding print: early reading development and the contributions of home literacy experiences," Journal of Experimental Child Psychology, vol. 93, no. 1, pp. 63-93, 2006.

[37] L. M. Phillips, R. Hayden, and S. P. Norris, Family Literacy Matters. A Longitudinal Parent-Child Literacy Intervention Study, Temeron, Calgary, Canada, 2006.

[38] K. Denton, J. West, and J. Walston, Reading-Young Children's Achievement and Classroom Experiences, National Center for Education Statistics: Findings from the Condition of Education, Washington, DC, USA, 2003.

[39] D. R. Entwisle and K. L. Alexander, "Factors affecting achievement test scores and marks of black and white first graders," The Elementary School Journal, vol. 88, no. 5, p. 449, 1988.

[40] P. Starkey and A. Klein, "Sociocultural influences on young children's mathematical knowledge," in Contemporary Perspectives on Mathematics in Early Childhood Education, pp. 253 276, Information Age Publishing, 2007.

[41] H. P. Ginsburg and R. L. Russell, "Social class and racial influences on early mathematical thinking," Monographs of the Society for Research in Child Development, vol. 46, no. 6, pp. $1-69,1981$.

[42] N. C. Jordan, S. C. Levine, and J. Huttenlocher, "Development of calculation abilities in middle-and low-income children after formal instruction in school," Journal of Applied Developmental Psychology, vol. 15, no. 2, pp. 223-240, 1994.

[43] H. P. Ginsburg, A. Klein, and P. Starkey, "The development of children's mathematical thinking: connecting research with practive," in Handbook of Child Psychology: Vol 4, Child Psychology in Practice, pp. 401-476, John Wiley \& Sons, New York, NY, USA, 5th edition, 1998.

[44] K. H. Seo and H. P. Ginsburg, "What is developmentally appropriate in early childhood mathematics education? Lessons from new research," in Engaging Young Children in Mathematics: Standards for Early Childhood Mathematics Education, pp. 91-105, Lawrence Erlbaum Associates, 2004.

[45] D. H. Clements, J. Sarama, and A. M. DiBiase, Engaging Young Children in Mathematics: Standards for Early Childhood Mathematics Education, Lawrence Erlbaum Associates, Mahwah, NJ, USA, 2004.
[46] National Association for the Education of Young Children and National Council of Teachers and Mathematics, Early Childhood Mathematics: Promoting Good Beginnings, Joint position statement on math, 2002.

[47] J. A. Lefevre, S. L. SKwarchuk, D. Kamawar, B. L. Smith-Chant, L. Fast, and J. Bisanz, "Home numeracy experiences and children's math performance in the early school years," Canadian Journal of Behavioural Science, vol. 41, no. 2, pp. 55-66, 2009.

[48] G. B. Saxe, S. R. Guberman, M. Gearhart, R. Gelman, C. M. Massey, and B. Rogoff, "Social processes in early number development," Monographs of the Society for Research in Child Development, vol. 52, no. 2, pp. 1-162, 1987.

[49] P. Starkey, A. Klein, I. Change, Q. Dong, L. Pang, and Y. Zhou, "Environmental supports for young children's mathematics development in China and the United States," in Society for Research in Child Development, Albuquerque, NM, USA, 1999.

[50] A. Klein and P. Starkey, "Preparing for the transition to school mathematics: the head start family math project," in P. Starkey (Chair). School Readiness and Early Achievement of Impoverished Children, in Symposium Conducted at the Meeting of the Society for Research in Child Development, Indianapolis, Ind, USA, 1995.

[51] P. Starkey and A. Klein, "Fostering parental support for children's mathematical development: an intervention with head start families," Early Education and Development, vol. 11, no. 5, pp. 659-680, 2000.

[52] C. Bowyer-Crane, M. J. Snowling, F. J. Duff et al., "Improving early language and literacy skills: differential effects of an oral language versus a phonology with reading intervention," Journal of Child Psychology and Psychiatry and Allied Disciplines, vol. 49, no. 4, pp. 422-432, 2008.

[53] C. M. Connor, F. J. Morrison, and L. Slominski, "Preschool instruction and children's emergent literacy growth," Journal of Educational Psychology, vol. 98, no. 4, pp. 665-689, 2006.

[54] R. W. Woodcock, K. S. McGrew, and N. Mather, Woodcock Johnson III Nu, Riverside Publishing, Rolling Meadows, Ill, USA, 2007.

[55] J. W. Creswell, W. E. Hanson, V. L. Clark Plano, and A. Morales, "Qualitative research designs: selection and implementation," Counseling Psychologist, vol. 35, no. 2, pp. 236-264, 2007.

[56] R. Whitley, "Introducing psychiatrists to qualitative research: a guide for instructors," Academic Psychiatry, vol. 33, no. 3, pp. 252-255, 2009.

[57] A. Strauss and J. M. Corbin, Basics of Qualitative Research: Grounded Theory Procedures and Techniques, Sage Publications, Thousand Oaks, Calif, USA, 1990.

[58] W. S. Barnett, "Early childhood education," in School Reform Principles: The Research Evidence, A. Molner, Ed., Information Age Publishing, Greenwich, Conn, USA, 2002.

[59] C. T. Ramey, S. L. Ramey, R. G. Lanzi, and J. N. Cotton, "Early educational interventions for high-risk children: how center-based treatment can augment and improve parenting effectiveness," in Parenting and the Child's World: Influences on Academic, Intellectual, and Social-Emotional Development, J. G. Borkowski, S. L. Ramey, and M. Bristol-Power, Eds., pp. 125140, Erlbaum Publishers, Mahwah, NJ, USA, 2002.

[60] T. P. Beauchaine, C. Webster-Stratton, and M. J. Reid, "Mediators, moderators, and predictors of 1-year outcomes among children treated for early-onset conduct problems: a latent growth curve analysis," Journal of Consulting and Clinical Psychology, vol. 73, no. 3, pp. 371-388, 2005. 
[61] C. Blair, "School readiness: integrating cognition and emotion in a neurobiological conceptualization of children's functioning at school entry," American Psychologist, vol. 57, no. 2, pp. 111-127, 2002.

[62] M. M. McClelland, C. E. Cameron, C. M. Connor, C. L. Farris, A. M. Jewkes, and F. J. Morrison, "Links between behavioral regulation and preschoolers' literacy, vocabulary, and math skills," Developmental Psychology, vol. 43, no. 4, pp. 947-959, 2007.

[63] F. J. Morrison, H. J. Bachman, and C. M. Connor, Improving Literacy in America: Guidelines from Research, Yale University Press, New Haven, Conn, USA, 2005.

[64] C. C. Raver, P. W. Garner, and R. Smith-Donald, "The roles of emotion regulation and emotion knowledge for children's academic readiness: are the links causal?" in School Readiness and the Transition to Kindergarten in the Era of Accountability, pp. 121-147, Paul H. Brookes Publishing, Baltimore, Md, USA, 2007.

[65] W. S. Barnett, K. Jung, D. J. Yarosz et al., "Educational effects of the Tools of the Mind curriculum: a randomized trial," Early Childhood Research Quarterly, vol. 23, no. 3, pp. 299-313, 2008.

[66] K. L. Bierman, C. E. Domitrovich, R. L. Nix, M. T. Greenberg, and C. Blair, "Executive functions and school readiness intervention: impact, moderation, and mediation in the Head Start REDI program," Development and Psychopathology, vol. 20, no. 3, pp. 821-843, 2008.

[67] C. E. Domitrovich, S. D. Gest, S. Gill, K. L. Bierman, J. A. Welsh, and D. Jones, "Fostering high-quality teaching with an enriched curriculum and professional development support: the head start REDI program," American Educational Research Journal, vol. 46, no. 2, pp. 567-597, 2009.

[68] A. Diamond, W. S. Barnett, J. Thomas, and S. Munro, "The early years: preschool program improves cognitive control," Science, vol. 318, no. 5855, pp. 1387-1388, 2007.

[69] W. S. Barnett, D. Yarosz, J. Thomas, and A. Hornbeck, Educational Effectiveness of a Vygotskian Approach to Preschool Education: A Randomized Trial, National Institute for Early Education Research, Rutgers University, New Brunswick, NJ, USA, 2006. 


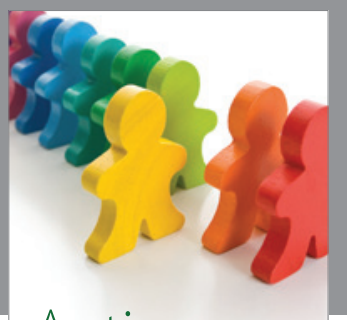

Autism

Research and Treatment
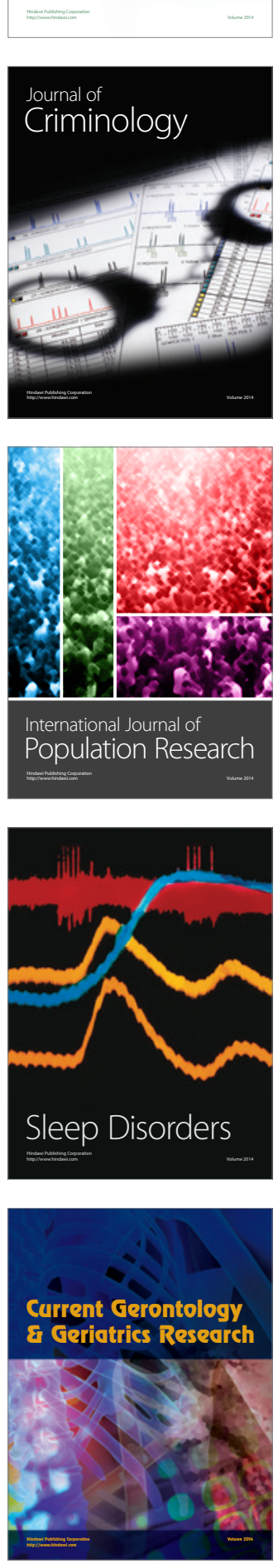
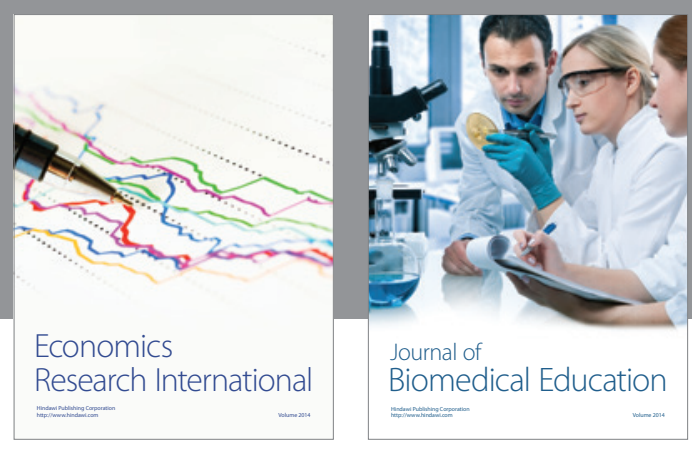

Journal of

Biomedical Education

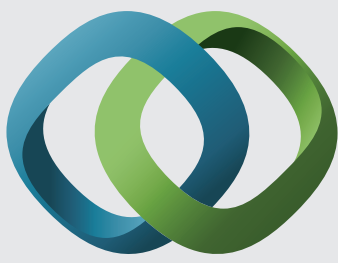

\section{Hindawi}

Submit your manuscripts at

http://www.hindawi.com
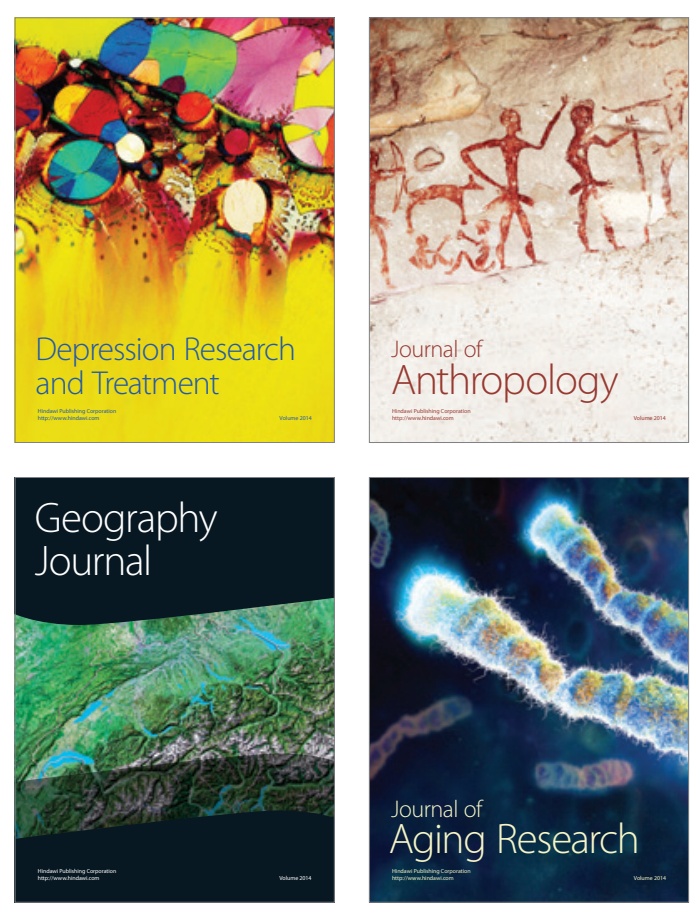

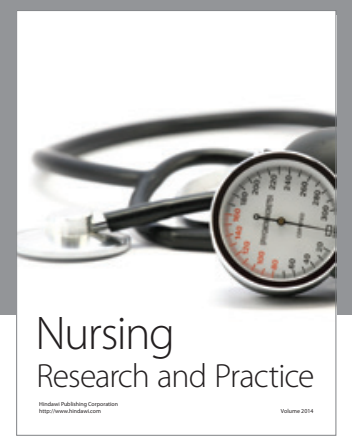

Nursing

Research and Practice

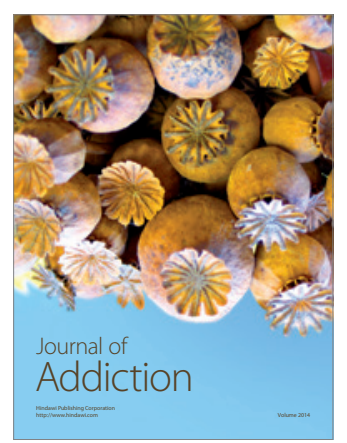

Child Development

Research

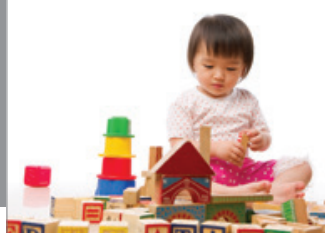

迥
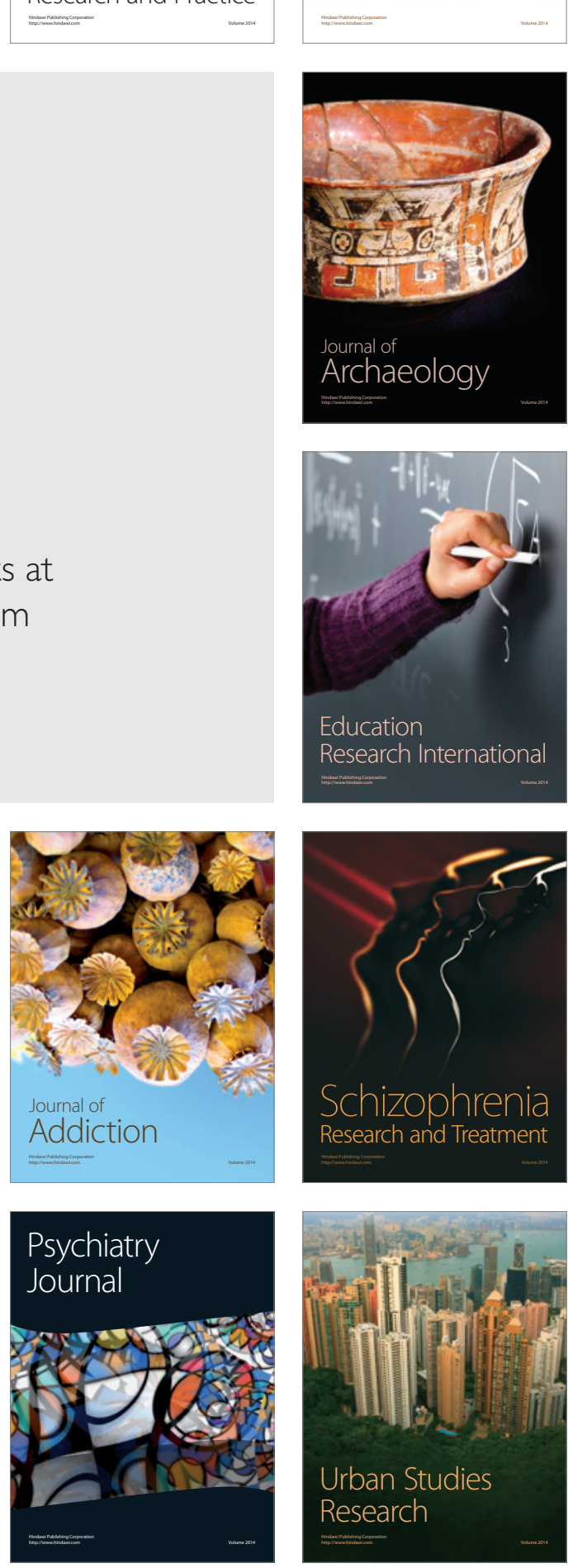